\title{
Effect of selenium deficiency on hepatic lipid and lipoprotein metabolism in the rat
}

\author{
BY F. NASSIR ${ }^{1 *}$, C. MOUNDRAS ${ }^{1}$, D. BAYLE ${ }^{1}$, C. SÉROUGNE ${ }^{2}$, E. GUEUX ${ }^{1}$, \\ E. ROCK ${ }^{1}$, Y. RAYSSIGUIER ${ }^{1}$ AND A. MAZUR ${ }^{1} \dagger$ \\ ${ }^{1}$ Centre de Recherche en Nutrition Humaine, Unité Maladies Métaboliques et Micronutriments, \\ INRA Clermont-Ferrand-Theix, 63122 Saint-Genès-Champanelle, France \\ ${ }^{2}$ Laboratoire de Physiologie de la Nutrition, Université Paris Sud, 91405 Orsay, France
}

(Received 18 November 1996-Revised 29 January 1997-Accepted 11 February 1997)

\begin{abstract}
Since experimental Se deficiency results in a significant increase in plasma cholesterol concentration the present investigation was undertaken to assess further the influence of this deficiency on the expression of proteins involved in hepatic lipid metabolism. Se deficiency was induced by feeding weanling male Wistar rats on a deficient diet for 6 weeks. Hypercholesterolaemia associated with Se deficiency was related to increased 3-hydroxy-3-methylglutaryl-coA (HMG-CoA) reductase (EC 1.1.1.34) activity in liver microsomes as compared with control animals. Hepatic lipoprotein receptor levels (LDL-receptor and HDL-binding proteins, HB1 and HB2) were not significantly affected by Se deficiency, as assessed by immunoblotting. Plasma triacylglycerol concentrations tended to decrease in Se-deficient rats in concert with their reduced post-Triton secretion. There was no significant effect of Se deficiency on the hepatic synthesis of apolipoproteins. These results point to the need for further investigations into the mechanism related to the increased activity of HMGCoA reductase and the enhanced cholesterogenesis in the liver of Se-deficient rats likely to result from this.
\end{abstract}

Selenium: Cholesterol: Triacylglycerol: HMG-CoA reductase

Several pieces of evidence indicate that Se deficiency may be related to cardiovascular diseases (Oster \& Prellwitz, 1990). Hypercholesterolaemia represents a recognized risk factor for atherosclerosis. Although human studies on the relationship between Se intake and plasma lipids are inconclusive, studies on the rat model indicate that Se deficiency results in a significant increase in plasma cholesterol level (Stone et al. 1986). This hypercholesterolaemic effect of Se deficiency appears to be potentiated by the addition of cholesterol to the diet (Stone, 1988; Stone et al. 1994). Recently we have shown that this increase in plasma cholesterol level is associated with changes in plasma lipoprotein and apolipoprotein concentrations (Mazur et al. 1996). In particular, we observed a marked rise in apolipoprotein (apo) $\mathrm{E}$ and $\mathrm{HDL}_{1}$ concentrations.

Since experimental Se deficiency in the rat induces a marked hypercholesterolaemia, the rat provides a good model for studying the mechanisms of this dyslipidaemia. Therefore, the present investigation was undertaken to assess further the influence of experimental Se deficiency on the expression of proteins involved in lipid and lipoprotein metabolism in the liver. Modifications in the expression or dysfunction of these proteins (receptors, enzymes, apolipoproteins) may cause disturbances in lipid metabolism and in turn give rise to hyperlipaemia.

* Present address: Department of Medicine, University of Chicago, Chicago, IL 60637, USA.

$\dagger$ For reprints. 


\section{MATERIALS AND METHODS}

\section{Animals and diets}

Male Wistar weanling rats (IFFA-CREDO, L'Arblesle, France) were fed for 6 weeks on either a control diet or a Se-deficient diet, twenty per group. Diet (containing $(\mathrm{g} / \mathrm{kg})$ : Torula yeast 300 , sucrose 590, tocopherol-stripped lard 50, salt and vitamin mixture without Se and vitamin E 60) was purchased from ICN Nutritional Biochemicals (Orsay, France). Vitamin E $(50 \mathrm{mg} / \mathrm{kg})$ as DL- $\alpha$-tocopheryl acetate (Sigma, l'Isle d'Abeau, France) was added to this diet. Se $(0.16 \mathrm{mg} / \mathrm{kg}$ as sodium selenite $)$ was added to make the control diet. Rats were housed in pairs in wire-bottomed cages in a temperature-controlled room $\left(22^{\circ}\right)$ with a dark period from 20.00 to 08.00 hours. Diet and distilled water were provided ad libitum. Body weight and food intake were recorded at 1-week intervals. All procedures were in accord with the Institute's guide for the care and use of laboratory animals.

\section{Blood and tissue sampling}

After 6 weeks of the experimental period, on the day of sampling, food was withdrawn at 08.00 hours. For biochemical analyses in the plasma and liver eight animals from each group were killed between 09.00 and 11.00 hours by exsanguination from the abdominal aorta after being anaesthetized with sodium pentobarbital $(40 \mathrm{mg} / \mathrm{kg}$ body weight) given intraperitoneally. Blood was collected into chilled tubes containing EDTA $(1 \mathrm{~g} / \mathrm{l})$ and plasma was obtained by low-speed centrifugation $(2000 \mathrm{~g})$. The liver was excised, blotted free of residual blood on the filter paper, weighed and portions from the right lobe were immediately plunged into liquid $\mathrm{N}_{2}$ before storage at $-80^{\circ}$ for further analyses. Liver microsomes were prepared from a portion of the fresh liver sample by the method of Einarsson et al. (1986), and frozen in liquid $\mathrm{N}_{2}$ and stored at $-80^{\circ}$. For the measurements of apolipoprotein synthesis in the liver and of triacylglycerol secretion six rats from each group were used. Experiments were carried out between 09.00 and 11.00 hours.

\section{Biochemical analyses}

Liver Se was determined spectrofluorimetrically, as previously described (Bellanger et al. 1992). Erythrocyte glutathione peroxidase (EC 1.11.1.9; GSH-Px) activity was measured according to the method of Paglia \& Valentine (1967) using cumene hydroperoxide as a substrate. Plasma triacylglycerol (Biotrol, Paris, France) and cholesterol (Biomérieux, Charbonnières-les-Bains, France) were determined by enzymic procedures using commercial kits. Liver samples were homogenized and lipids were extracted with chloroform-methanol (2:1, v/v; Folch et al. 1957). Triacylglycerol and cholesterol concentrations were measured in the lipid extracts as previously described (Mazur et al. 1990). The total microsomal 3-hydroxy-3-methylglutaryl-coA (HMG-CoA) reductase (EC 1.1.1.34) activity was measured as described by Wilce \& Kroone (1992). Labelled mevalonolactone was separated from unreacted HMG-CoA by column chromatography using AG1-X8 resin (200-400 mesh, formate form; Bio-Rad, Paris, France). A portion of each liver was also used for determination of fatty acid synthetase ( $E C$ 2.3.1.85; FAS) activity according to the method of Hsu et al. (1969), except that $\left[2-{ }^{14} \mathrm{C}\right]$ malonyl-CoA was used as tracer (Maeda et al. 1975). The FAS activity was expressed as nmol ${ }^{14} \mathrm{C}$-labelled long-chain fatty acid formed/g liver per min. 


\section{Plasma apolipoprotein analyses}

Plasma apolipoprotein concentrations were determined by radial immunodiffusion using sheep anti-rat apolipoprotein antisera obtained in our laboratory (Felgines et al. 1994). Plasma samples were diluted with Nonidiet P40 ( $5 \mathrm{ml} / 1$ final concentration) for apo B and apo $\mathrm{E}$ assays and with urea ( $7 \mathrm{M}$ final concentration) for apo A-I and apo A-IV assays. Serially diluted purified rat LDL and HDL fractions were used as assay standards.

\section{Lipoprotein receptor levels in the liver}

Total membranes from frozen liver samples were prepared according to the method of Kovanen et al. (1979). Solubilized membrane proteins ( $8 \mu \mathrm{g}$ in $50 \mu \mathrm{l}$ samples) were spotted onto nitrocellulose membranes using a a dot-blot apparatus. After incubation for $1 \mathrm{~h}$ in a quenching buffer containing bovine serum albumin $(50 \mathrm{~g} / \mathrm{l})$ for saturating all the nonspecific sites, nitrocellulose membranes were incubated for 90 min with the antibody raised against the LDL receptor (kindly provided by $\mathrm{P}$. Roach, Adelaide, Australia; dilution 1:500) or with those raised against two HDL-binding proteins, HB1 and HB2, (kindly provided by N. Fidge, Melbourne, Australia; dilution 1:500), considered as putative HDL receptors (Tozuka \& Fidge, 1989; Mathai et al. 1990). Then, after washings, membranes were incubated for $90 \mathrm{~min}$ with an anti-rabbit IgG conjugated with horseradish peroxidase (dilution 1:1000). The complexes formed between the receptors and their antibodies were revealed by coloured chemical reaction (with chloro-naphthol). The relative intensity of each spot, determined on wet nitrocellulose membranes using a laser densitometer (Ultroscan 2202; LKB, Bromma, Sweden) was expressed as peak height (mm). The receptor amounts are given in arbitary units taking results obtained from controls as $100 \%$.

\section{Apolipoprotein synthesis rates in the liver}

For the measurement of apolipoprotein synthesis rates in the liver six control and Sedeficient rats were injected intraportally with $37 \mathrm{MBq}$ L-[4,5,3]leucine (specific activity $5.29 \mathrm{TBq} / \mathrm{mmol}$; Amersham, Bucks.; Baum et al. 1990). Quantitative immunoprecipitation of apolipoproteins was performed on liver homogenates using polyclonal rabbit antisera directed against rat apo A-I, A-IV, E and B. Obtained immune complexes were washed extensively and separated on denaturing SDS-PAGE disc gels (50 or $75 \mathrm{~g}$ acrylamide/ $)$ ). Gels were sliced and radioactivity was determined by liquid scintillation spectrometry (Kontron, St Quentin-en-Yvelines, France) following the addition of $3 \%$ ProtosolEconofluor (NEN, Boston, MA) to gel slices. Total protein synthesis (TCA-insoluble radioactivity) was not significantly different between the two groups (controls 98 (SE 11), Se-deficient 85 (SE 13) counts/min per $\mu$ g protein). Data are expressed as a percentage of total protein synthesized.

\section{Triacylglycerol secretion}

For the measurement of the triacylglycerol secretion rate six control and six Se-deficient rats were injected intravenously with Triton WR 1339 (Tyloxapol, Sigma), an inhibitor of plasma triacylglycerol hydrolysis, and the increase in plasma triacylglycerol concentration was monitored. The procedure was exactly the same as previously described (Nassir et al. 1993). The results are expressed as nmol triacylglycerol secreted/min per $100 \mathrm{~g}$ body weight. 


\section{Statistical analysis}

Results are expressed as means with their standard errors. Comparisons between groups were made by Student's $t$ test. The differences were considered significant at $P<0.05$.

\section{RESULTS}

Body weights of Se-deficient rats were not significantly affected after 6 weeks on the deficient diet (Table 1). In rats fed on diets without Se, low levels of Se in the liver and low GSH-Px activity in erythrocytes were consistent with severe Se deficiency (Table 1). Plasma cholesterol concentrations were significantly greater and those of triacylglycerol tended to be lower $(P<0 \cdot 1)$ in Se-deficient rats than in the control group (Table 1). The concentration of plasma apo $E$ was increased in Se-deficient animals (Table 2). There was no significant effect of Se deficiency on the hepatic synthesis of apolipoproteins (Table 2). Lipid concentrations in the liver were not significantly different among experimental groups (Table 3). HMG-CoA reductase in liver microsomes was significantly higher in Sedeficient rats than in control rats (Table 3). FAS activity and lipoprotein receptor (LDL, HB1 and HB2) levels in the liver were not significantly affected by Se deficiency (Table 3). Se-deficient rats presented reduced post-Triton secretion of triacylglycerols (Table 3).

\section{DISCUSSION}

In agreement with previous studies from Stone's group (Stone et al. 1986, 1994; Stone, 1988) and our group (Mazur et al. 1996) in the present study we have shown that Se deficiency in the rat results in increased plasma cholesterol concentration. Additionally, we demonstrated that Se-deficient rats displayed an increase in apo E concentration. As we have previously shown, both increased plasma cholesterol and apo E concentrations in these rats are related to an increase in the $\mathrm{HDL}_{1}$ fraction (Mazur et al. 1996), which is particularly rich in apo $\mathrm{E}$ (Lusk et al. 1979). $\mathrm{HDL}_{1}$ plays an important role in the reverse transport of cholesterol in the rat and we have found in our previous studies that this lipoprotein fraction is particularly responsive to dietary conditions (Mazur et al. 1990; Nassir et al. 1994; Sérougne et al. 1995). To understand the origin of this rise in plasma cholesterol and more specifically in $\mathrm{HDL}_{1}$ in Se-deficient rats we have evaluated some of the mechanisms related to the formation and removal of lipoproteins that might be responsible for such an effect. Since it is well known that fasting markedly modifies the expression of proteins involved in lipoprotein metabolism (Davis et al. 1989; Baum et al. 1990) the present study was carried out on non-fasted animals.

The major significant mechanism which could be involved in the observed hypercholesterolaemia in Se-deficient rats is the increased activity of HMG-CoA reductase in the liver. Since HMG-CoA reductase is the rate-controlling enzyme of cholesterol biosynthesis this observation suggests an increased hepatic cholesterogenesis in Sedeficient animals. As previously discussed by us (Sérougne et al. 1995) the linear relationship between the $\mathrm{HDL}_{1}$ concentration in the plasma and HMG-CoA reductase activity in the liver of rats in various dietary conditions strongly suggests that newly synthesized hepatic cholesterol is involved directly in $\mathrm{HDL}_{1}$ formation. In addition, increased formation of $\mathrm{HDL}_{1}$ could result from an increased supply of the surface components of triacylglycerol-rich lipoproteins (Eisenberg, 1980). In the rat, a species devoid of cholesteryl ester transfer protein (Oschry \& Eisenberg, 1982), $\mathrm{HDL}_{1}$ is generated in plasma from more dense HDL particles that are progressively loaded with cholesteryl esters and enriched with apo E. The surface material released from VLDL lipolysis 


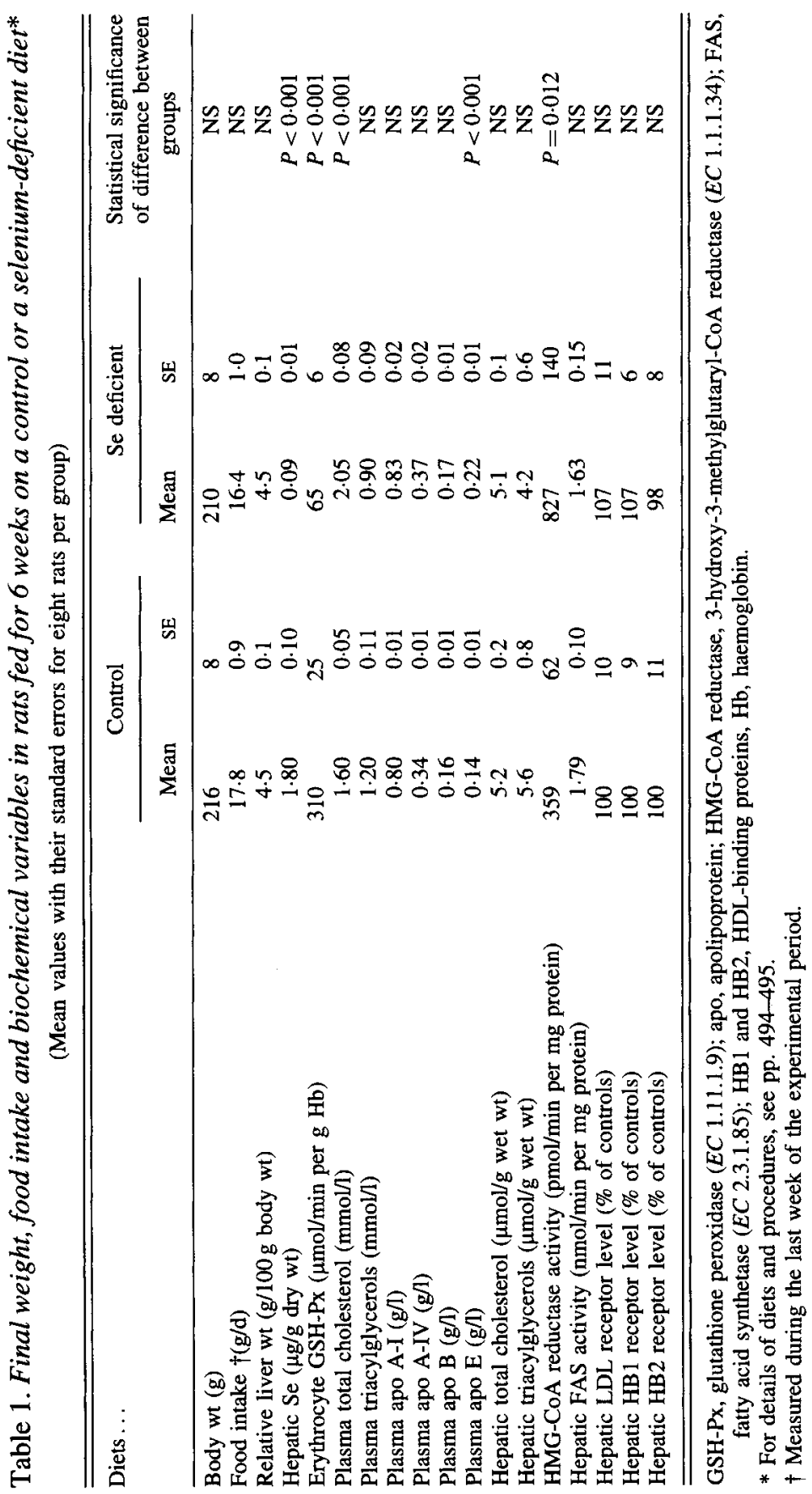


Table 2. Apolipoprotein synthesis in the liver and triacylglycerol secretion rate in rats fed for 6 weeks on a control or a selenium-deficient diet*

(Mean values with their standard errors for six rats per group)

\begin{tabular}{|c|c|c|c|c|c|}
\hline \multirow[t]{2}{*}{ Diets... } & \multicolumn{2}{|c|}{ Control } & \multicolumn{2}{|c|}{ Se deficient } & \multirow{2}{*}{$\begin{array}{c}\text { Statistical significance } \\
\text { of difference between } \\
\text { groups }\end{array}$} \\
\hline & Mean & SE & Mean & SE & \\
\hline \multicolumn{6}{|l|}{$\begin{array}{l}\text { Liver synthesis (\% of TCA- } \\
\text { insoluble radioactivity) }\end{array}$} \\
\hline Apo A-I & 0.66 & $0 \cdot 10$ & 0.61 & 0.05 & NS \\
\hline Apo A-IV & 0.33 & 0.02 & 0.34 & 0.01 & NS \\
\hline Apo B100 & $0 \cdot 11$ & 0.02 & 0.08 & 0.01 & NS \\
\hline Apo B48 & 0.39 & 0.07 & 0.35 & 0.08 & NS \\
\hline Apo $\mathrm{E}$ & 1.57 & 0.18 & 1.41 & 0.09 & NS \\
\hline $\begin{array}{l}\text { Triacylglycerol secretion rate } \\
\text { (nmol triacylglycerol/min } \\
\text { per } 100 \mathrm{~g} \text { body wt) }\end{array}$ & 0.416 & 0.008 & 0.332 & 0.012 & $P<0.001$ \\
\hline
\end{tabular}

Apo, apolipoprotein.

* For details of diets and procedures, see pp. 494-495.

represents a major source of $\mathrm{HDL}_{1}$-apo $\mathrm{E}$ (Oschry \& Eisenberg, 1982; Gavish et al. 1987). However, in the present study we have demonstrated that Se deficiency is not associated with increased fatty acid synthesis and VLDL secretion by the liver as shown by unmodified FAS activity and reduced post-Triton triacylglycerol secretion. These results differ from previous work by Scott et al. (1991) in which hepatic synthesis of VLDL in Sedeficient spontaneously hypertensive rats fed on a cholesterol-enriched diet was evaluated by using an isolated liver perfusion system. It was found that Se deficiency resulted in increased hepatic production of the lipid moiety of VLDL and the authors suggested that the decreased fatty acid oxidation in the liver of Se-deficient rats provides a stimulus for the secretion of newly synthesized VLDL. A defect in thyroid hormone metabolism has been proposed as a possible mechanism for such a modification in lipid metabolism (Stone et al. 1994). This discrepancy between these observations undoubtedly results from the nutritional conditions used in these studies. It is well known that cholesterol feeding of animals leads to profound modifications in lipid and lipoprotein metabolism (Mahley \& Holcombe, 1977; Sérougne et al. 1995) and it might be hypothesized that an interaction exists between Se deficiency and dietary cholesterol resulting in the specific modifications in the liver metabolism previously observed by Scott $e t$ al. (1991).

A low expression of lipoprotein receptors could also be related to an increase in plasma cholesterol. In the present study we evaluated the level of LDL and two HDL receptors (HB1 and HB2) in the liver. Our results indicate that the modification in the level of LDL receptor is not involved in the Se-deficiency-induced hypercholesterolaemia. Measurement of the level of two HDL-binding proteins also showed that they are not modified by this deficiency. This last observation is concordant with the lack of the effect of Se deficiency on the $\mathrm{HDL}_{2}$ fraction and apo A-I levels (Mazur et al. 1996). In fact, it has been shown that these proteins have an apparent specificity for HDL devoid of apo E (Tozuka \& Fidge, 1989). However, since we showed that apo E synthesis in the liver was not affected by Se deficiency the possibility exists that the increase in $\mathrm{HDL}_{1}$ concentrations may result from their decreased clearance. Other receptors, especially those binding apo E, may be 
implicated in this dysregulation. Oxidative modifications of lipoproteins that may occur during Se deficiency may also be of importance by modifying their metabolic fate.

These results point to the need for further investigations into the mechanisms by which Se deficiency leads to hypercholesterolaemia. In particular, the mechanism related to the increased activity of HMG-CoA reductase and the enhanced cholesterogenesis in the liver likely to result from this should be evaluated. HMG-CoA reductase is subject to multiple regulatory mechanisms, including protein synthesis and degradation, feedback control by sterols, endocrine regulation by a variety of hormones, and phosphorylation. In the other model of hypercholesterolaemia induced by $\mathrm{Cu}$ deficiency, Kim et al. (1992) have proposed that the rise in hepatic glutathione concentration, resulting from the compensatory response to a deficit in superoxide dismutase (EC 1.15.1.1) and GSH-Px, could be responsible for the high HMG-CoA reductase activity. In fact, HMG-CoA reductase possesses cysteine residues and is subject to regulation by thiol-disulfide exchange (for review, see Bunce, 1993). During Se deficiency the level of Se-dependent GSH-Px is markedly decreased and it has been shown that Se deficiency suppresses Sglutathiolation of another enzyme (carbonic anhydrase III) under oxidative stress (Lii \& Hendrich, 1993). Further investigations will be necessary to ascertain if this mechanism may contribute to the Se-deficiency-induced hypercholesterolaemia.

We thank A. Bellanger, J. Bellanger and C. Lab for their excellent technical assistance. This project was supported by a grant from ARCOL.

\section{REFERENCES}

Baum, C. L., Teng, B.-B. \& Davidson, N. O. (1990). Apolipoprotein B messenger RNA editing in the rat liver. Modulation by fasting and refeeding a high carbohydrate diet. Journal of Biological Chemistry 265, 1926319270.

Bellanger, J., Bouvier, J. C. \& Lab, C. (1992). Dosage du sélénium dans le vin par spectrofluorimétrie. Application à quelques vins français (Selenium level in wine measured by spectrofluorimetry. Application to some French wines). Journal International des Sciences de la Vigne et du Vin 26, 287-293.

Bunce, G. E. (1993). Hypercholesterolaemia of copper deficiency is linked to glutathione metabolism and regulation of hepatic HMG CoA reductase. Nutrition Reviews 51, 305-307.

Davis, R. A., Dluz, S. M., Leighton, J. K. \& Brengaze, V A. (1989). Increased translatable mRNA and decreased lipogenesis are responsible for augmented secretion of lipid-deficient apolipoprotein $E$ by hepatocytes from fasted rats. Journal of Biological Chemistry 264, 8970-8977.

Einarsson, K., Angelin, B., Ewerth, S., Niessel, K. \& Bjorkhem, I. (1986). Bile acid synthesis in man: assay of hepatic microsomal cholesterol 7-alpha hydroxylase activity by isotope dilution-mass spectrometry. Journal of Lipid Research 27, 82-88.

Eisenberg, S. (1980). Plasma lipoprotein conversion: the origin of low density and high-density lipoproteins. Annals of the New York Academy of Sciences 348, 30-47.

Felgines, C., Sérougne, C., Mathé, D., Mazur, A. \& Lutton, C. (1994). Effect of simvastatin treatment on plasma apolipoproteins and hepatic apolipoprotein mRNA levels in the genetically hypercholesterolaemic rats (RICO). Life Sciences 54, 361-367.

Folch, J., Lees, M. \& Sloane-Stanley, G. H. (1957). A simple method for the isolation and purification of total lipids from animal tissues. Journal of Biological Chemistry 226, 497-506.

Gavish, D., Oschry, Y. \& Eisenberg, S. (1987). In vivo conversion of human HDL3 to HDL2 and apo E-rich HDL1 in the rat: effects of lipid transfer protein. Joumal of Lipid Research 28, 257-267.

Hsu, R. Y., Butterworth, P. H. W. \& Porter, J. W. (1969). Pigeon liver fatty acid synthase. In Methods in Enzymology, vol. 14, pp. 33-39 [J. M. Lowenstein, editor]. New York: Academic Press.

Kim, S., Chao, P. Y. \& Allen, K. G. D. (1992). Inhibition of elevated hepatic glutathione abolishes copper deficiency cholesterolaemia. FASEB Journal 6, 2467-2471.

Kovanen, P. T., Brown, M. S. \& Goldstein, J. L. (1979). Increased binding of low density lipoprotein to liver membranes from rats treated with $17 \alpha$-ethinyl estradiol. Journal of Biological Chemistry 254, 11367-11373.

Lii, C.-K. \& Hendrich, S. (1993). Selenium deficiency supresses the S-glutathiolation of carbonic anhydrase III in rat hepatocytes under oxidative stress. Journal of Nutrition 123, 1480-1486. 
Lusk, L. T., Walker, L. F., Dubien, L. H. \& Getz, G. S. (1979). Isolation and characterization of high-density lipoprotein HDL1 from rat plasma by gradient centrifugation. Biochemical Journal 183, 83-90.

Maeda, H., Ikeda, I. \& Sugano, M. (1975). Behavior of the liver key lipogenesis enzymes in rat threonine imbalanced diet. Nutrition Reports International 12, 61-66.

Mahley, R. W. \& Holcombe, K. S. (1977). Alterations of the plasma lipoproteins and apolipoproteins following cholesterol feeding in the rat. Journal of Lipid Research 18, 314-324.

Mathai, D., Fidge, N., Tozuka, M. \& Mitcheli, A. (1990). Regulation of hepatic high density lipoprotein binding proteins after administration of simvastatin and cholestyramine to rats. Arteriosclerosis 10, 1045-1050.

Mazur, A., Nassir, F., Gueux, E., Moundras, C., Bellanger, J., Grolier, P., Rock, E. \& Rayssiguier, Y. (1996). Diets deficient in selenium and vitamin $\mathrm{E}$ affect plasma lipoprotein and apolipoprotein concentrations in the rat. British Journal of Nutrition 76, 899-907.

Mazur, A., Rémésy, C., Gueux, E., Levrat, M. A. \& Demigné, C. (1990). Effects of diets rich in fermentable carbohydrates on plasma lipoprotein levels and on lipoprotein catabolism in rats. Journal of Nutrition 120 , 1037-1045.

Nassir, F., Mazur, A., Felgines, C. \& Rayssiguier, Y. (1993). Age related response to dietary fructose in the rat: discrepancy in triglyceride and apo B synthesis as a possible mechanism for fatty liver induction in adult rats. Proceedings of the Society for Experimental Biology and Medicine 204, 180-183.

Nassir, F., Mazur, A., Gueux, E., Sérougne, C. \& Rayssiguier, Y. (1994). Apolipoprotein A-I, A-IV and E synthesis in the liver of copper-deficient rats. Lipids 29, 727-729.

Oschry, Y. \& Eisenberg, S. (1982). Rat plasma lipoproteins: re-evaluation of a lipoprotein system in an animal devoid of cholesteryl ester transfer activity. Journal of Lipid Research 23, 499-507.

Oster, O. \& Prellwitz, W. (1990). Selenium and cardiovascular disease. Biological Trace Element Research 24, 91-103.

Paglia, D. E. \& Valentine, W. N. (1967). Studies on the quantitative and qualitative characterization of erythrocyte glutathione peroxidase. Journal of Laboratory and Clinical Medicine 70, 158-169.

Scott, R. L., Kheshti, A., Heimberg, M., Wilcox, H. G. \& Stone, W. L. (1991). The role of selenium in the secretion of very-low-density lipoprotein in the isolated perfused liver. Biochemical Journal 279, 741-745.

Sérougne, C., Felgines, C., Férézou, J., Hajri, T., Bertin, C. \& Mazur, A. (1995). Hypercholesterolemia induced by cholesterol- or cystine-enriched diets is characterized by different plasma lipoprotein and apolipoprotein concentrations in rats. Joumal of Nutrition 125, 35-41.

Stone, W. L. (1988). The effects of cholesterol supplementation on plasma lipoprotein-cholesterol levels in rats fed diets deficient in vitamin $\mathrm{E}$ and/or selenium. Nutrition Research 8, 1061-1071.

Stone, W. L., Scott, R. L., Stewart, E. M. \& Kheshsti, A. (1994). Lipoprotein alterations in the spontaneously hypertensive rat fed diets deficient in selenium and vitamin E. Proceedings of the Society for Experimental Biology and Medicine 206, 130-137.

Stone, W. L., Stewart, M. E., Nicholas, C. \& Pavuluri, S. (1986). Effects of dietary selenium and vitamin E on plasma lipoprotein cholesterol levels in male rats. Annals of Nutrition and Metabolism 30, 94-103.

Tozuka, M. \& Fidge, N. (1989). Purification and characterization of two high-density-lipoprotein-binding proteins from rat and human liver. Biochemical Journal 261, 239-244.

Wilce, P. \& Kroone, P. A. (1992). Assay of 3-hydroxy-3-methylglutaryl coenzyme A reductase. In Lipoprotein Analysis - A Practical Approach, pp. 203-214 [C. A. Converse and E. R. Skinner, editors]. Oxford: Oxford University Press. 